\title{
Pre-print
}

"Paper for DISCOURSE \& SOCIETY"

Title: Parental discourse and identity management in the talk of indigenous and migrant speakers

Maria Xenitidou and Sara Greco Morasso

V2.0 18/9/2013

\section{Parental discourse and identity management in the talk of indigenous and migrant speakers}

\begin{abstract}
This article integrates discursive psychology and argumentation studies to discuss the regularities identified in two sets of data - focus group discussions amongst indigenous Greeks residing in Central Northern Greece and interviews with non-indigenous women with children, resident in the greater London area. The initial regularity identified consisted of participants talking as parents and talking about children and the normative expectations of parenthood in voicing strong views about 'others' from ethnic, cultural and racial backgrounds other than those of the speakers. This seemed to function as a form of denial, identifying further regularities in the discursive strategies used by participants and in the lines of arguments developed. Furthermore, two themes emerged as commonplace in talking about 'others' in the lines of argument developed by participants - security/insecurity and hierarchies. These regularities are considered and the potentials of analysing discourse from two, integrated approaches are discussed.
\end{abstract}

\section{Keywords}

Discursive psychology, argumentation studies, identity, migration, otherness, strong views, denial, parenthood, Greece, UK

\section{Introduction}

This article emerged as a result of working with two different sets of data - focus group discussions amongst indigenous Greeks residing in Central Northern Greece and interviews with non-indigenous women with children in the greater London area. It was interesting to note in these sets of data a regularity consisting of parental positioning (talking as a parent) and topicalization (talking about children and the normative expectations of parenthood) in voicing strong views about 'others' from ethnic, cultural and racial backgrounds other than those of the speakers. In order to understand the regularity we observed better, we attempt to approach it analytically from two perspectives - discursive psychology and argumentation studies, thus contributing an integrated insight into the ways in which identity is managed in talking about ethnic, cultural and racial 'others'. 
The article consists of five main sections. In the next section the integrated insight employed for studying strong views is explored: we introduce strong views and then attempt to summarize the two perspectives as well as their points of (i) epistemological and (ii) analytic convergence. Subsequently, the two study cases are considered and the sets of data are presented. In the Discussion the regularity we identified is discussed focusing on its functions. Finally, in the Conclusions we reflect on the insights gained in discussing the regularity identified from an integration of two perspectives.

\section{Bringing different traditions together in studying strong views}

In this article we focus on voicing strong views through an emergent regularity - talking as parent and talking about children and the normative expectations of parenthood in voicing strong views about 'others' from ethnic, cultural and racial backgrounds other than those of the speakers. Billig (1989) argues that views in general and strong views in particular are held in contexts of controversy, i.e. in relation to opposing views. Therefore, the discourse associated with strong views 'should be an argumentative discourse' (Billig, 1989: 210). Views in argumentative discourse have a duality arising from the rhetorical nature of argumentation: they are views about something, but also, exist in an argumentative context and have to be supported 'against' present or absent competitors. Therefore, in the process of justifying and criticizing views, participants become also enmeshed in justifying and criticizing the arguments upholding views and counterviews, which engages them in reflecting upon the grounds of their own and of others' arguments. The more unpopular (or counter-normative) a view, the more argumentative possibilities exist and the stronger an opposition it is likely to invite, which in turn calls upon more argumentative moves and manoeuvres.

Having laid out the argumentative nature of holding strong views, we now turn to integrate insights in order to better capture this phenomenon. We draw on discursive psychology and argumentation studies, which while being epistemologically and methodologically compatible, have not been often integrated in the analysis of discourse. Therefore, our approach requires some justification in terms of theoretical convergence as well as in terms of micro-analytic techniques used in the analysis.

\section{Converging perspectives on discourse and discursive strategies}

Discursive psychology and argumentation studies share converging lines on identity management as well as a general view on the argumentative nature of discursive practices. Both approaches may come under the general label of Discourse Analysis (DA) (Edwards, 2005: 258; Plantin, 2002), sharing a concern for naturally occurring discourse in real life interactions (Edwards and Potter, 1992: 28; Potter, 2012). They are oriented towards practices manifested in language rather than on cognitive processes. Argumentation studies and discursive psychology also share an interest in the function of discourse - people's goals (action-orientation) and the rhetorical/discursive strategies used to obtain these goals ${ }^{\mathrm{i}}$. 
'Discursive Psychology' (DP) is a term initiated by Edwards and Potter (1992) on the principle that social actions are being done in discourse, focusing on the ways accountability is managed and factualisation or fact construction achieved, and on the premise that every utterance claims 'truth', otherwise arguing is rendered pointless. Therefore, reports or descriptions are designed rhetorically to undermine and resist being undermined, while managing identity implications for speakers.

Similarly, the focus of argumentation studies is on understanding how arguers resolve their difference of opinion through a reasonable debate, while trying to win their cause (van Eemeren, 2010). An argumentative analysis is centred on the speakers' goals, as these are externalised in discourse. Individuals who have a difference of opinion are at the centre of the analytic attention, while texts provide the necessary data to analyse the means by which they (re)solve their difference of opinion.

In this article, we draw on the pragma-dialectical approach to argumentation (van Eemeren and Grootendorst, 1984, 2004; van Eemeren, 2010), in particular. This is a normative model, as it describes what characteristics a discursive exchange should have in order to count as argumentative - oriented towards the resolution of a difference of opinion by reasonable means. Therefore, the model is used as a heuristic standard to reconstruct argumentation from real communicative exchanges as well as for understanding the functions of argumentative discourse. We will complement this model with a view on argumentation rooted in text analysis $^{\text {ii }}$ (Rigotti and Greco Morasso, 2009). In an argumentative discussion, each arguer wants to win his or her cause (rhetorical aim) and is motivated to do so within the boundaries of reasonableness (dialectical aim). Rhetorical and dialectical aims are enmeshed and, therefore, maintaining the balance between the commitment to reasonableness and being effective means that the arguers have to manoeuvre strategically in all moves that are carried out in an argumentative discussion (van Eemeren and Houtlosser, 2002, van Eemeren, 2010). In particular, strategic manoeuvring manifests itself in the discourse through three aspects: 'A particular choice made from the available topical potential, a particular way in which the opportunities for framing the addressee's perspective are used [audience demand], and a particular way in which presentational possibilities are exploited [presentational devices]' (van Eemeren and Houtlosser, 2009: 6).

DP conceptualizes social life as both normative and rhetorical. Normativity here refers to the normative ways of talking and the expectations of social life. Rhetoric is treated as orientated to persuasion for however good the rhetoric, there is no guarantee that persuasion takes place (Billig, 1989).

It becomes clear from the above that both argumentation studies and DP stem from the tradition of ancient rhetoric and its emphasis on persuasion (Billig, 1996; Rigotti and Greco Morasso, 2009). In argumentation studies, rhetorical goals are regarded as a general label to indicate the arguers' pursuit to win their cause (van Eemeren, 2010). Though argumentation is ideally characterized by reasonableness, the desire to win and to persuade others of one's view is the profound reason why someone should engage in an argumentative discussion in the first place (Rigotti and Greco Morasso, 2009). The focus of argumentation studies is on 
the rhetorical strategies adopted by the individual arguer, as he or she is engaged in a dispute with some other. DP draws on rhetorical psychology by emphasizing the contextboundedness of meaning as well as the ideological history of words and utterances, in the sense that they are attached to discourses which are socially and contextually shared - in other words a society's or culture's common sense (Billig, 1987, 1991, 2001; Billig et al, 1988). Common sense is argued to be marked by a contrary nature in the sense that socially and contextually shared themes (commonplaces) are rhetorically organized. Discourse is, therefore, rhetorical in terms of both content and practices: 'it is argumentative and seeks to persuade; as such the activities of criticism and justification are central to rhetorical discourse' (Billig, 2001: 214). Commonplace contrary themes and conflicts of values may be used in flexible ways, often to achieve common purposes, thus presenting dilemmas in arguing.

From this dilemmatic outlook to common sense, it seems that persuasion and intersubjective agreement - that is the assumption that only one view could be right - integral to argumentation. Strong ways of eliciting or of engaging in qualifications of evaluation and of discounting the views of others might be relevant in 'forcing' agreement. At the same time, people tend not to argue the virtues of personal preferences as there is a normative imperative for multisubjectivity, which permeates issues of accountability: individuals differ in their views, and all individuals have equal rights to hold 'their own opinion'. This might also enable strong views as claiming that one speaks from their point of view fences off the speaker and achieves sticking to one's own opinion while embracing liberal principles of 'freedom of speech' and, thus, appearing as rational and enlightened. Besides this functional rhetorical explanation of views, views are also accounts of social reality (Billig, 1987: 217) and why certain utterances are formulated instead of others in the context of discussion should be interrogated. In that respect, voicing views in interaction consists in negotiations of versions of social reality, the analysis, therefore, necessitating a focus on the lines of argument developed for sense-making (Wetherell, 1998).

As discussed above, in DP the argumentative nature of talk is considered within a broader ideological (Billig et al, 1988) context, in which dilemmas are 'conserved synchronically in the ideological common-sense of contemporary society' (Billig, 1989: 219; on the interface between society and discourse, ideology and discourse, and dilemmas as a consequence of multiple allegiances, see van Dijk, 1995). Although argumentation studies consider the role of context (Rigotti and Greco Morasso, 2009; van Eemeren, 2010), they do not take into account such a meso-view of ideological dilemmas in society and of their influence on specific rhetorical and discursive strategies. Also, the emphasis on the rhetorical goal is stronger in DP, yet not at the expense of accountability and reasonableness (Ihnen and Richardson, 2011: 240, footnote 1). Therefore, not only are the two approaches compatible, but they can also be resourcefully integrated to enhance each other. We discuss this integration in the ways in which we approach the micro-analysis of our data in the subsequent section. 


\section{Micro-analytic techniques}

Speakers' appeal to reasonableness (accountability) and truth claims (fact construction) in general, and in voicing strong views in particular, manifest itself in talk through various discursive strategies. In keeping with a rational moral profile, speakers voicing strong views about others might engage in denial strategies, the use of which has been identified with reference to ethnic and racial others (van Dijk, 1992). These include 'disclaimers, mitigation, euphemism, excuses, blaming the victim, reversal and other moves of defense, face-keeping and positive self-presentation in negative discourse about minorities, migrants and (other) anti-racists' (van Dijk 1992: 87). According to van Dijk, generally denials are part of a strategy of defense, presupposing explicit or implicit accusations; 'yet sometimes denials may also be pre-emptive [...] that is, they may focus on possible inferences of the interlocutors' (van Dijk 1992: 91).

In considering all of the above strategies and how they relate to voicing strong views, we draw on different traditions including sociology, rhetorical and discursive psychology, argumentation studies, linguistics and discourse analysis, acknowledging the variability in the use of terms and origin. We have nevertheless decided to make this acknowledgment as both DP and argumentation studies tap into these traditions for the analysis of discourse.

The definition of disclaimers, one of the most common strategies of denial, ranges from 'semantic moves' (van Dijk, 1992) to 'interactional tactics' (Hewitt and Stokes, 1975) employed to 'forestall' criticisms that the view which is about to follow is known to produce. Hewitt and Stokes (1975) argued that disclaimers are employed in view of emergent meanings being threatened or situational identities discredited. In that respect, disclaimers attend both to content - what is said - and accountability - how and from what footing it is said. In the DP tradition, disclaimers are strategies found in managing the dilemma of stake or interest, namely 'how to produce accounts which attend to interests without being undermined as interested' (Edwards and Potter, 1992: 158). They, therefore, consist of phrases used to disavow or mitigate agency and claim 'objectivity' on a position which has been or is about to be discursively enabled (Billig, 1991) and could potentially be hearable as 'problematic'. In argumentation studies, the corresponding notion to that of discursive psychology is prolepsis (see also Billig, 1989). Known as a rhetorical strategy since antiquity, prolepsis has been recently studied as a means to position the speaker in a favourable way (Leff, 1999; Leff and Goodwin, 2000; Clauss, 2007) and frame the issue in an acceptable way for the audience (Snoeck-Henkemans, 2007). Prolepsis is understood as the anticipation of possible objections against the arguer's standpoint and is, therefore, crucial to the management of implicit differences of opinion, whereby the 'other' addressed, responded to or countered is constructed on the basis of what is potentially expected. With regards to talking about minorities and migrants in particular, van Dijk $(1992,1995)$ argues that disclaimers are used to introduce racist discourse, presenting the in-group positively (as being tolerant) or denying a negative property (being racist), while expressing a negative property for the out-group. 
While disclaimers are often conflated with 'mitigating devices', we draw a distinction here, treating mitigation as another form of denial consisting of downtoning, minimizing or using euphemisms that overall function to 'minimize' what is said and/or the responsibility of the speaker. Van Dijk (1992) argues that mitigation strategies are particularly prominent in social situations where the relevant norms are strong; the stronger the norm against discrimination and racism, the more people will tend to use denial strategies to avoid the stigma of prejudice (see Gaertner and Dovidio, 2005). We find that the above take on mitigation corresponds to Caffi's (2007) three sets of mitigation devices developed in linguistics: bushes, hedges and shields. Bushes, such as diminutive forms, intervene at the linguistic level of a proposition. Hedges modify the sentence's illocutionary force; in assertive speech acts, in particular, the speaker's commitment to the truth-value of his or her statement is attenuated, e.g. 'I'd propose you if you want to see if I can make you sleep' (Caffi, 2007: 102) iii. Shields concern the 'deictic origin' of the utterance, for example, shifting the responsibility of what is said from the speaker to a general, undefined other (Caffi, 2007: 107), e.g. through the use of passive voice.

While terminology varies, shielding the speaker's identity is also a central analytic concern for DP. For example, the language associated with the dilemma of stake or interest, apart from disclaimers also comprises impersonal, 'out-there' (Potter, 1996) structures which function to blur agency and disavow accountability. Relevant to the above are the microsociological notions of footing and face that DP draws on as analytic devices of the manifestation and management of accountability. Footing as developed by Goffman (1981) refers to alignment in relation to what is occurring in interaction and to speakers' local identity orientation to the utterances they produce (Antaki, Condor and Levine, 1996). In other words, footing refers to how one relates to what one says. Face refers to ' $[\mathrm{T}]$ he positive social value which a person effectively claims for himself by the line others assume he has taken during a particular contact' (Goffman, 1967: 5). Van Dijk (1992) refers to face-keeping or positive self-presentation as part of the overall strategy of 'impression management'. This notion matches accountability as it entails catering for others' judgements.

Apart from denial and impression management strategies associated with voicing strong views, and in keeping with our overall integrative analytic approach, we focus on fact and interest as features of the content and organisation of discourse. These refer to fact construction and the dilemma of stake or interest, namely formulating accounts that are both convincing and disinterested, thus, constructing responsibility in various ways; for example, script formulations describe actions in ways that treats them as normal - what anyone in the given situation would do - and therefore beyond individual agency. While we have discussed attending to interests and identities above, in terms of fact construction techniques of particular relevance to this article from DP we draw on: Category entitlement, Vivid and vague description, Extreme Case Formulations (ECF) (Pomerantz, 1986), Consensus and Corroboration, Lists (Jefferson, 1990) and Contrasts, Rhetoric of Argument (Edwards and Potter, 1992: 160-3; Potter, 1996: 166-9). In terms of argumentative strategic manoeuvring focal in argumentation studies, the construction of arguments can be analysed in terms of argument schemes - a term which refers to the inferential configuration of an argument and 
hints at the relation between a standpoint and the discourse produced in order to support its validity (Rigotti and Greco Morasso 2010). Argument schemes may be classified depending on the principle of (inferential) support (Garssen, 2001), linking an argument to a standpoint. An argument scheme is based, for instance, on analogy, if the standpoint is supported by an argument pointing at the analogy of the situation described in the standpoint with another situation; for example 'This country will recover from the financial turmoil, as it recovered from past crises'. Other argument schemes are based on cause-effect argumentation, meansend argumentation (pragmatic argumentation), example, authority, etc. (Rigotti and Greco Morasso, 2010).

In the Discussion, we draw analytically on the principles of DP and critically integrate them with notions from argumentation studies when relevant to enhance our understanding of participants' talk. In order to contextualize this understanding, we present information on our data below.

\section{The two cases: data and background}

The first set of data comes from a focus-group based study conducted 2004-6 where Greek people residing in urban and rural central northern Greece were asked to talk about Greek national identity and immigration in Greece. Greece appears as a destination country for immigrant populations from Eastern Europe and the former Soviet Republics since 1989, and, post-2005, from North Africa, South Asia and the Middle East ${ }^{\mathrm{iv}}$. Taking that into account, the target population of the study was Greek citizens and ethnic Greeks who were born and raised in Greece, Central Northern Greece, in particular, owing to a reported high percentage of immigrants from the neighbouring Balkan countries ${ }^{\mathrm{v}}$ (NSSG, 2001). Eight semi-structured focus group sessions were held, with 39 participants selected using snowball sampling, in the process of which age (18-21 and 35-45) and locality (rural and urban) were considered important. The focus group discussions were recorded, transcribed and discourse analysed based on the premises of discursive psychology described in the previous section (for a detailed description of the method and research process see Xenitidou, 2007, 2010).

The second set of data was collected as part of the project 'Migrants in transition: an argumentative perspective, ${ }^{\text {, }}$. The project focused on migrants' reported inner dialogue during their process of displacement. Twenty-nine mothers aged 25-50, who had migrated to the UK, were interviewed about their experience of international displacement. At the time of the study (September 2010-March 2011), the interviewees were resident in the greater London area. In contrast to the trajectory of immigration in Greece, the UK has been a receiving country for years (Coleman and Salt, 1992) and London is especially characterized by superdiversity (Vertovec, 2007), which made the focus on this city relevant to understanding how migrants react to encounters with others. Participants were diverse in terms of linguistic, ethnic and cultural origin, number of children, work-family balance, migration strategy and family status. In-depth reconstructive interviews were used to reconstruct how participants lived a moment of rupture and the following transition a posteriori (Zittoun, 2009: 415). The interviews were transcribed for a subsequent argumentative and linguistic analysis. 
Therefore, our corpora differ in terms of method (focus groups and interviews), context (type of migration and receiving country) as well as participants' positions and expected footing (indigenous in the first study, migrants in the second). As regards the method, while focus groups enable intersubjectivity, which personal, one to one interviews may not equally enable, people tend not to argue the virtues of personal preferences as there is a normative imperative of multisubjectivity. Thus, the assumption that we all have opinions coexists with the counter-assumption that we should also have (or reach) some sort of understanding between us (Billig, 1989). This co-existence might not be enabled per se in one to one interviews where the researcher assumes the role of interviewer rather than that of the fellow discussant; yet the normative principles of 'own opinion' entitlement but also of 'corroboration' as an appeal to rationality are manifested in interaction regardless of method. For example, interview participants' addressees seemed to be relatives, friends and other acquaintances, whose arguments the participants relayed expressing doubts and objections (Greco Morasso, forthcoming).

As regards footing, different affordances might be available and expected from our participants' subject positions - indigenous Greeks talking about immigrants in Greece and migrants in London talking about their experience in the UK. While this is a matter of empirical scrutiny, we take both dialogue and power into account in subscribing to the position that 'the self is configured in dialogic responsiveness to prior and anticipated patterns in dialogue' (Bakhtin, 1984 in Lock and Strong, 2012, p. 98), yet acknowledging that not all anticipated patterns have equal standing and not all selves are uttered from the same footing (see for example Parker, 1989).

\section{Discussion}

In the discussion that follows, we examine the ways in which strong views about others are articulated while presenting oneself as a reasonable arguer; i.e. as someone who is not articulating these views out of self-interest per se and is not prejudiced or racist. Namely, we study how parental positioning and/or topicalization offers speakers an opportunity to ground and, in this way, mitigate their strong views on people other than their (own) ethnic, cultural and racial/colour group. By parental positioning and topicalization, we refer to both participants talking as parents to justify their strong views as grounded on worries about their children (as an expectation of parenthood); and to participants mobilizing the category of parent and the normative expectations of parenthood to draw distinctions between their (own) in-group and 'other' out-groups. In our extracts, parental positioning and topicalization emerge as connected to two themes, which seem, thus, to emerge in turn as thematic regularities for speakers' strong views about migration: security/insecurity and hierarchies.

\section{Otherness and Security}

The first two extracts are related to security/insecurity; otherness is viewed as a source of potential insecurity and, ultimately, a potential threat to one's established identity.

Extract 1 ${ }^{\text {vii }}$ - Janet (New Zealand, 44) 
Our first extract is taken from the corpus of migrant mothers. It comes from an interview with Janet who is wedded to an English man and has two children.

1 Janet: [...] (.) and we live in ((place)) currently which to me is not you

2 know the school they go is a Catholic school so a lovely school but

3 the actual area would be much (..)

4 Sara: Really?

5 Janet: It's very I don't mean to say this in a racist form it's very

6 multicultural (.) and so sometimes the people (.) have to push up

7 how you bring your children up >you know? < And (.) you know if

8 I had more money I would move towards London where I first

9 flatted and down the Surrey way you know I have friends down

10 there and (.) and it's just a much nicer way of life for the children

11 I mean (.) here I send them to a Catholic school my partner is

12 Catholic (.) ah but the surrounding schools (.) you know they

13 would be a minority (.) ethnic white English and it's still you know

14 (.) though they're born in England (..) probably 95\% (.) Asian and I I

15 you know that huge: (..) yeah all kinds of cultures so children (.)

16 have a mix of that at school but it's a balance (.) you know not the

17 main and I want them to appreciate all cultures that's what I'm doing

18 in this country appreciating (.) all the cultures but I just don't want

19 them to be a minority in their own country (.) and so actually (.) for

20 them to grow up as teenagers in this area (.) that will worry me so: I

21 don't know what I (.) the area worries me or the country it's a

22 mixture I suppose (.) but if I had the money I would (..) now (.) and

23 as I said some close friends are doing that now (.) you know they're

24 moving for the children who are teenagers to give them (.) that sort

25 o:f [...]

Starting with general considerations about the area she lives in, Janet moves to explicitly position herself as a parent in line 2 - 'the school they go'. The reference to children is constructed as the main reason why Janet does not consider herself a racist. At the level of strategic manoeuvring, the most important aspects are the shifts in footing through which Janet expresses her worries in terms of children's needs (lines 6, 7, 10, 15 and 23-24). Such shields allow Janet to construct non-I strategies, thereby reducing accountability. The main strategy when Janet's utterances are not shielded seems to be disclaimer-prolepsis, through which not only the stigma of racism is managed (line 5) but also the stigma of intolerance towards other cultures claiming to be 'appreciating all the cultures' in the UK (lines 17-19). In light of the notion of strategic manoeuvring, the reiterated use of prolepsis is associated with the choice at the level of topical potential to describe the situation in terms of a lack of a balance (line 16). The choice of the term balance frames the situation in such a way that Janet's strong view becomes more acceptable in light of her claimed openness to multiculturalism. Thus, Janet's argument is supported in two ways: the imbalance implied is considered negative - as imbalanced situations would in general - while potential accusations for the stigma of intolerance this may bear are managed.

The association of otherness to security emerges in connection to these disclaimers and shifts in footing, shielding the speaker, and is explicitly manifested from line 18 onwards, when 
Janet uses the verb 'to worry' twice referring to her children growing up in her area. The difficulty with which this association emerges is also indicated by the use of pauses and hedges. Janet, thus, positions herself as a concerned parent and, grounds a fear about her children's upbringing on them being a racial minority. This fear is warranted by a reference to numbers (95\% Asian) and financial means - 'if I had the money' - thus constructing the area comprising 95\% Asian as deprived. However, beyond her position as a mother, Janet draws a clear distinction of ownership and privilege for the native and against the 'other', in this case the Asian other, by constructing her children as a native minority outnumbered by, by implication, Asians as non-natives. While Janet is a non-native resident as well, 'native' is constructed in terms of colour rather than nationality.

\section{Extract 2 - Focus Group 8 (Mixed Gender, 35-45)}

The second extract comes from a focus group discussion with participants who reside in the centre of Thessaloniki, central northern Greece, and have children (Vera and Panos, below, have two children each).

944 Vera: that is to say my childhood years have no relation to now (.) and my child I

945 would like ((it)) to experience some things and is not going to experience them

946 ever (.) is not going to experience them ever (.) to understand what

947 neighbourhoo:d means

948 Panos: in this in this the immigrants are to blame o::r the urbanisation?

949 Vera: now is to blame what is to blame the urbanisation is to blame:

950 Panos: =if there were all Greeks in the neighbourhood it would be better?

951 Vera: e::h maybe I'd have more I'd be more: free to ((her)) playing with

952 Katerina wi:th Ioanni rather than now that I know that there is one Katerina and

953 one Ioannis (.) and there would be further down Abraha:m, Abdul Allah

954 thi:s $>$ that I don't know where he comes from and where he goes and what is

955 going on $<$

In talking about the effects from immigration in Greece, Vera formulates a temporal comparison between past and present as an extreme case of change (line 944). She then formulates a wish the addressee of which is her child, which she emphatically forewords the wish with (lines 944-945). The content of the wish is for Vera's child to understand what neighbourhood means and is rhetorically formulated to emphasize that this will not come true (line 945-947). In mobilising her child, Vera uses a rhetorical tactic of voicing the sort of commonplace sentiment with which it is difficult to disagree (Billig, 1989). The shift in footing (lines 944-945) is evidently related to this strategy, as parental responsibility and worries for how children grow up are generally considered as justifiable. As in the previous extract, through these shifts in footing the empowered child emerges as a legitimate arguer in a cultural domain in which children's rights are highly valued. Speaking as a mother, therefore, both shields Vera and enables appeals to a commonplace sensitivity about children, reducing accountability for her sayings while underlying their importance.

Panos picks up the point of temporal changes and points to the causes rather than the effects which are implicitly entailed in Vera's account- counter posing immigrants with urbanisation (line 948). To this, Vera explicitly addresses a generalised blame in a vague way, suggesting 
that the effect is the point of focus, and in so doing sustaining immigrants' accountability for both change and for its effects (line 949). Panos then more explicitly links effect to cause, by inviting Vera to respond to a script according to which national homogeneity - 'all Greeks' 'would be better' (line 950). After initial hesitation, Vera follows the script by referring to the degree of responsibility as a mother to provide a secure environment for her child. Vera associates this with familiarity which is defined in terms of national homogeneity allowing a sense of 'freedom' with reference to security (lines 951-3). The agents of this break-up of homogeneity are vaguely categorised with 'tag names' which suggest reference to religious rather than national categories, namely Jewish and Muslim ${ }^{\text {viii }}$ (lines 953-4). The points of otherness and lack of familiarity are constructed in a three-part list as origin, course and practices, which functions to present abstract images of 'others' as commonplace, conventional and factual. In this vague formulation, immigrants are not directly related to the compromise of security but through being constructed as 'others' whose presence dissolves national homogeneity (Wimmer and Schiller, 2002). While this might be heard as problematic for Vera's moral profile, her footing as a mother seems to come with a normative appeal to worrying and protection.

\section{Construction of Hierarchies}

The next three extracts entail the elements of security and homogeneity but are mostly exemplar of axiological accounting about 'others' with reference to the wellbeing of the children.

\section{Extract 3 Anastasia (Lithuania, 30)}

Anastasia, mother of a toddler (boy), is talking about the reasons why she and her husband (from Italy) wish to leave London.

1 Sara: So you want to move at a certain point in the future but you don't

2 know

3 Anastasia: Ah (..) well yes I would like somewhere in Europe but (.) I mean

4 yeah we can even move in Italy but not in Naples 'cause (.) I I

5 mean to come and visit it's okay but to live there for forever no

6 Sara: Okay (.) okay and that's something you ah thought after he was

7 born not before he was born

8 Anastasia: Yeah yeah 'cause (..) I mean I don't wanna be a racist but:

9 when you look around ((laughter)) (.) so it's it's not that I:

10 would like to live here

11 Sara: Yeah you mean for the people he would meet (.) at school or:

12 Anastasia: Eh yeah because (.) I mean (.) I've met some mothers here (.)

13 like Ukrainian we're going to the same classes (.) hh ah (..) and

$\mathbf{1 4}$ for me it's just (.) like (.) I don't know say (.) one of these girls'

15 son he's very very blonde (.) VERY very blonde and: (.) yeah it

16 was a few months ago that: we receive those newspapers about

17 (name of the Borough) there were pictures about school pictures

18 school children (.) and I've been looking I said oh my gosh or

19 we need to find a Catholic school or:: or it's gonna be like a

20 sunshine ((laughter)) 
21 Sara: Really?

\section{Anastasia: $\mathrm{Oh}$}

23 Sara: You mean because it's very:: well in ((name of the borough)) you

24 have lots of Indians I suppose

25 Anastasia: A lot

26 Sara: So schools the public schools are: (.) well if you go to (name) but

27 that's a private school that's very: ((laughter)) [...]

28 Anastasia: Yes for this reason I think (.) 'cause (.) yeah when I was single I

29 just rented a flat (.) e:h (.) fla:t A room I used to rent a room and

30 the: (.) the girl that she rents me she had a daughter and the

31 daughter is quite big now I think she's thirteen years old but at

32 that time maybe nine or something (.) and it's unbelievable she

33 said (.) ALL other like in the school Indian girls and she's got the

34 hair lice in the hair oh my gosh she said (.) hh

35 Sara: I imagine they can be very:: very different social levels in

36 ((borough)) (.) and also where I live

37 Anastasia: It's EVERYWHERE I think but (.) I don't know for me it's

38 really SOMETHING and it's just they they just don't care even

39 if they got teachers they cannot do anything you just need to act

40 yourself and like for okay you have brains so ( ) like these

41 little ones they don't think (.) so: if they would take your hat they

42 would put on you and: it's it's a shame

The interviewer reformulates a previous discussion in which Anastasia had said that she intends to move out of London at some point on which Anastasia elaborates listing and comparatively evaluating possible destinations (lines 1-5). The interviewer's question in lines 6-7, asking whether she had decided to leave London before or after her child was born, is suggestive of a connection between such decision and parental responsibility. Anastasia picks up this connection and for most of the extract she justifies why she does not want her child to live in their current place of residence. Similarly to Janet (Extract 1) Anastasia's account is forwarded by a disclaimer-prolepsis for her narrative of colour difference to follow - 'I don't wanna be a racist but' - anticipating an implicit argumentative discussion. In this way, Anastasia positions herself in a group, whose members have the right to discuss about other non-white people. In terms of strategic manoeuvring, the speaker positions herself as part of a rational audience, whose members are against racism. In addition to that, in line 9, Anastasia attempts a first shift in footing - 'when you look around' - inviting her interlocutor to corroborate. After this, she moves to assuming parental footing (from line 12 and, then explicitly, from line 37), which is characteristic of her denial strategies insofar as it represents the main basis on which she legitimates her strong views about a social hierarchy between white children (lines 14-15, 31) and darker-coloured children, mainly identified with Indians (line 33). The shift in footing is a form of mitigation shielding the strong views she has expressed against others, who are constructed as contagiously dirty. This shift is justified as part of parental responsibility, because children cannot be aware of the danger (lines 40-41) ${ }^{\mathrm{ix}}$. Lines 39-42 topicalize normative expectations about parenthood and what parents should do for their children, disclaiming a possible counter-argument that this is teachers' role and justifying parents taking matters in their own hands. 
It should be noted that Anastasia's child is very young and not of school age yet. This could render Anastasia's argumentation unsupported, because she lacks knowledge about the system she is describing. The strategy she adopts to support her argument is examples about children in local schools taken from indirect experiences. Anastasia's narrative, therefore, mostly draws on other people's examples to support, without being singled out, initially a colour difference as problematic - 'it's gonna be like a sunshine' - and then a cultural difference -'Indian girls and she's got the hair lice' - as problematic on the basis of hygiene. In DP, examples and personal experience have a fact construction function as their eventuality cannot be questioned. In argumentation studies, example is an argument scheme based on the logical principle 'ab esse ad posse valet illatio': if something happened in one case, it is possible, and, therefore, could happen again. However, several studies have warned about the risk of undue generalization (van Eemeren and Grootendorst, 1987; Rigotti, 2005) associated with the use of examples. While Anastasia's account falls into this problem, the two examples she uses still retain the power of showing actual situations which might otherwise not be deemed possible ${ }^{\mathrm{x}}$.

The example used to ground worries about her child's hygiene, in particular, appears to be in line with the thesis of illusory correlations (Hamilton and Gifford, 1976) in social psychology according to which (unwarranted) associations are made between two variables characteristics and social groups - especially in case of unfavourable behaviour and/or atypical events. This refers to correlations of characteristics - 'hair lice' - with group membership - 'Indian'. Illusory correlations are argued to be more easily drawn between minority groups and undesirable behaviours based on a shared distinctiveness; the minority status here implicit in racial rather than numerical terms.

\section{Extract 4 - Focus Group 2 (Male, 35-45)}

On the same lines, but grounding difference and progress on reasons other rather than hygiene, the next extract is presented as an example of evaluative comparisons implied between Greeks and immigrants in Greece. The extract comes from a focus group with male participants who reside in areas scattered across Thessaloniki, central northern Greece, of which two (Manolis and Costas) have one child each.

698 Manolis: can I ask you something else? Me does it bother me today if my 699 daughter says today with today's - my daughter is five years old eh - if my $\mathbf{7 0 0}$ daughter tells me "I want to marry an Albanian" does it bother me with today's 701 conditions because logically $>$ not because he is Albanian though $<$ whatever I say $\mathbf{7 0 2}$ or whatever stuck up I have in my mind it bothers me that with today's economic $\mathbf{7 0 3}$ terms logically he will be a little worker. In twenty years twenty five if the time 704 comes to tell me tha:t

Manolis formulates a hedged personal hypothesis to respond to charges of prejudice against immigrants in Greece. The hypothesis is formulated by Manolis positioning himself as a father and using a rhetorical tactic of voicing the commonplace sentiment of care for the wellbeing of one's children - his daughter in this case. The wellbeing of his daughter is not aligned with her being wedded to an Albanian immigrant, using a disclaimer (line 701). He 
goes on to discount whatever he might say or think about Albanians as ungrounded prejudice countering it with the 'real reason' - constructed as commonplace - that he will be a 'little worker' (line 703). The economic status of Albanians in Greece, while hedged, is constructed as the source of the problem with Greeks, the source, therefore, of reasonable prejudice (Billig et al, 1988). This might still be heard as problematic but is justified on the basis of caring for the wellbeing of his daughter.

Manolis' example lacks grounding in reality, which he also explicitly disclaims - 'my daughter is five years old' (line 699). As in the case of Anastasia, he supports this lack of experience by recourse to an example, consisting of a hypothetical projection in which his daughter might want to marry an Albanian, vividly uttered by using active voicing (line 700). Positioning himself as a parent and relaying his daughter's possible words has the function to allow a projection to a possible situation in which Manolis would have some reason to be bothered by an immigrant's social status, because this would affect his family. This rhetorical move functions to factualise a low economic status for immigrants in Greece compared to Greeks while responding to accusations of prejudice on the part of Greeks. Treating prejudice in this way to respond to charges of it indicates that prejudice based on socio-economic characteristics is commonly more acceptable than that based on national stereotypes. However, Manolis is double insulated against accusations of prejudice as not only is he constructing the reasons for prejudice as 'pragmatic' but also mobilising 'affective' reasons to justify his stake on the matter.

\section{Extract 5 - Focus Group 4 (Female, 35-45)}

The last extract comes from a focus group with female participants residing in a village in Halkidiki, central northern Greece, who talk about levels of 'caring' for children as embedded in national cultures.

106 Christina: do you mean in other words that they don't care about their 107 relations eh [with the Greeks?

108 Sofia: [yes. they care about how to raise money:

109 Toula: apart from this

110 Sofia: thei:r relationship with the Greeks may be seemingly good but their

111 purpose is to raise money (.) to go and make houses (.) NOTHING else (..) I have

112 talked to Anna and I have talked to Eri (..) and the one works in the store and the 113 other I have her [at home

114 Christina: [guys every person who migrates, right, who is a labour migrant 115 comes for a specific purpose he doesn't go just like this because

116 Toula: [you don't flatten everything out Christina

117 Joanna: [we too went to Germany but ((overlapping))

118 Sofia: the Greeks were not the same when they went to Germany

119 Christina: that is to say what? Didn't they have as a purpose to make

120 houses?

121 Toula: =you don't flatten [everything

122 Sofia: [didn't they care about the level of thei:r

123 children and the studies of their children? 
Sofia constructs immigrants in Greece as not caring about anything but raising money in response to Christina's direct question (lines 106-108, 111). This is strengthened by her claim to be entitled to talk about immigrants and her appeal to personal experience (lines 112-113), and thus to author the point in a disinterested yet strong manner. Namely, Sofia makes use of an example - 'I have talked to Anna and I have talked to Eri' in support of her view (lines 111-113). However, her example may be challenged for being insufficient to justify the preceding generalization (ECF) - that immigrants only care about making money and buying houses. Christina challenges Sofia's argument by universalising the purposes of labour migrants beyond the two cases offered using a global formulation (lines 114-5). By appealing to the category of 'labour migrant', Christina provides a functional genus, the underlying principle of which is that all labour migrants should be evaluated in the same way (Rigotti and Greco Morasso, 2010). Christina's (re-)categorisation of immigrants in Greece into the common, superordinate category of 'labour migrants' taps into the thesis of the common ingroup identity model in social psychology (Gaertner et al, 1990; Gaertner and Dovidio 2000, 2005), according to which if members of the groups in contact are recategorised into a common, super-ordinate category, in-group favouritism for this new, common category will contribute to the reduction of prejudice.

The argument from analogy inferred is nevertheless readily met with the mobilisation of the category of the Greek emigrant in Germany. In this endeavour, Joanna breaks the potentially inferred analogy and contrasts Greek emigrants to immigrants in Greece speaking from the category of Greek emigrants to Germany by using the first person plural - 'we' - aligning with that category without nevertheless having that background (line 117). This is continued by Sofia who makes a vague claim about the difference between Greek emigrants and immigrants in Greece appealing to conventional knowledge in a seemingly disinterested manner as it seems to suffice to say that 'Greeks were not the same'. Sofia's comparison between Greek emigrants and immigrants in Greece as two different categories, is based on another argument from analogy: two different situations need to receive a different evaluation. The functional genus identified by Christina - 'labour migrant' - is thus denied, initiating a meta-discussion on what can be considered to be analogous situations which escalates in Toula's reiterated turn, formulated as an extreme case, constructing 'flattening out everything' as factual for immigrants in Greece. The content of this is then explicitly articulated by Sofia who continues to oppose the functional genus (as the basis of analogy) and counters 'everything' with the 'care for children', which underlines the degree of seriousness of 'care' and epitomises the lack of care on the part of immigrants. In mobilising the category of children, Sofia uses a rhetorical tactic of voicing the sort of commonplace sentiment of care for children and for their education, with which it is difficult to disagree, thus forcing intersubjective agreement. Thus, on the one hand immigrants in Greece care about 'NOTHING' but raising money and making houses while Greek emigrants in Germany cared about the level and studies of their children. By establishing a hierarchy of migrants' based on care for their children as the ultimate criterion on which difference is grounded (lines 122-123), Sofia contrasts the analogy formulated by Christina and constructs a hierarchy in which Greek emigrants feature higher than immigrants in Greece. 


\section{Conclusions}

The present article has shown the ways in which topicalizing parenthood and talking as a parent enabled the voicing of strong views about people of origin - ethnic, cultural and racial - other than the speakers. We have focused on this as a regularity consisting of parental positioning and topicalization as a form of denial found within two different sets of datafocus group discussions with indigenous Greeks talking about identity and immigration in central northern Greece and interviews with non-indigenous women with children in London. We analysed both sets of data from a discourse analytic perspective combining DP and argumentation studies. Our emergent understanding of this regularity was that it presented a form of denial which functioned to inoculate participants against the negative identity that may derive from accusations of prejudice. We have analysed how topicalizing parenthood and talking as a parent enabled participants to construct prejudice as reasonable in five extracts, in which we have analysed all discursive strategies common in the denial of racism, focusing in particular, on disclaimers and mitigation as these were most commonly used. Apart from focusing on the rhetorical organisation of our participants' utterances, we also noted the content of their utterances and identified that the regularity above was mainly related to two themes: security/insecurity and (the construction of) hierarchies. Therefore, the regularities identified were threefold: parental positioning and topicalization in voicing strong views in our data, deriving from different social and discursive contexts; discursive, as parental positioning and topicalization functioned as and made use of denial strategies; and thematic, in making issues of security and hierarchies relevant in talking about others.

More specifically, our findings concern parental positioning as a form of (shift in) footing and parental topicalization as a form of accounting about parenthood which enables the mobilization of commonplaces - children, caring for and protecting them and worrying about their future. In the Discussion, we presented exemplary extracts on the basis of their main thematic orientation (security and hierarchies respectively). We identified the uses of disclaimers and mitigation, as well as of argument schemes - in particular examples and analogies - and discussed the (lines of) arguments developed around them. In paying close attention to how but also what is being said, two main lines of argument have been identified. In Extracts 1 and 2 participants position themselves as parents and topicalize parenthood by mobilizing commonplace concerns about their children's future which they associate with the presence of others. This is made through the use of numbers and an example (Extract 1), and a temporal comparison and hypothetical projection (Extract 2), on which participants ground the association between the presence of 'others' and issues of safety and security, while constructing their concerns as 'reasonable'. In Extracts 3, 4 and 5 participants position themselves as parents and topicalize parenthood and mobilize commonplace concerns about children which are used as criteria for grounding hierarchies. In these hierarchies the in-group is preferentially treated in comparison to 'others' who are constructed as worse off in terms of hygiene, socio-economic status and value-system using examples (Extracts 3 and 4) and analogy (Extract 5). It should be noted that in the context of these discussions, 'significant others' for Greeks are immigrants - Albanians in one case - while othering for migrant mothers in London is achieved by reference to colour and race (Bozatzis, 2009 for a 
discussion of the ideological grounding of the rhetorical articulation of hierarchical distinctions, albeit between the West and the Rest; see van Dijk, 1995 for the normativity of tolerance as a socio-cultural value (of the West) allowing for the expression of prejudice as unproblematic).

In both lines of argument, a commonly used argument scheme is example. Examples could be categorized according to their temporality: in Extracts 1 and 3 accounts are focused on the future as the problem of encountering otherness is projected at a time when children will enter secondary school or reach school age respectively; Extracts 2 and 4 hypothesize potential situations; in Extract 5 an example is used but in support of the argument as based on personal experience rather than as a future or hypothetical projection. All in all, however, it seems that temporality and its relation to the use of examples present common ways of talking as parent and topicalizing parenthood to voice strong views about others while denying prejudice and racism. This may be considered an exploitable insight for further research (see also van Dijk, 2012, on local coherence and evidentiality).

In addition, beyond the immediate context of discussion that our extracts come from, the regularity identified allows some further considerations about parental positioning and topicalization and the denial of racism as a phenomenon which has important socio-political as well as cultural implications. One explanation for the regularity identified in our data could be the distinction made by van Dijk (1992) between negative evaluations about one's personality, on the one hand, and a particular action in one specific situation, on the other. According to van Dijk, (1992), 'to be categorized as 'a racist' or even as being 'intolerant', presupposes an enduring characteristic of people, and is therefore a judgment that is particularly face-threatening' (pp. 89-90) and, therefore, managed through 'denial' strategies such as disclaimers, mitigation and even reversal. Overall, positive self-presentation and negative other presentation is a well-known strategy which exhibits ideological structures in discourse. Therefore, discourse structures manifest and enable 'underlying ideologies', particularly with reference to the affordances made for 'us' and 'them', our good things and their bad things (van Dijk, 1995, 2012). The ideological underpinning of this regularity may be further explored drawing on the thesis of ideological dilemmas, in particular, the ideological dilemma of prejudice and tolerance embedded in liberal ideology. According to this dilemma, prejudice is condemned as it is associated with irrational views held against 'other' social - racial or national - groups and, ultimately with racism and nationalism, while people are framed by collective forms of allegiance which divide social groups into different sets of 'others' (Billig et al, 1988). This dilemma is reproduced in lay discourse as the morally acceptable thing to do is to denounce it while being divided into 'us' and 'them'; in this process the dilemmatic aspect of prejudice evolves as a reasonable, justifiable and rational form of prejudice, based on (the mobilization of) examples correlating categories to particular behaviours and generalizing upon them by attributing characteristics to group membership, and/or external events dissociated from any agency on the part of the prejudiced individual (Billig et al, 1988: 100-123; Billig, 2012). Prejudice is, therefore, masked as a 'rational estimate' predicated upon others' value system, hygiene levels, socio-economic status, upbringing and 'otherness'/fear of the unknown (Figgou et al, 2011). In this 
framework, talking and positioning oneself as parent functions to (double) inoculate against accusations of prejudice and racism, grounding the voicing of strong views about others on commonplace sensitive topics - children, their safety and wellbeing - and constructing concerns around them as pragmatic. Taking this explanation into account, our article contributes to the stream of research using discursive strategies to analyse (national) identity, otherness, prejudice and racism beyond fact/value dilemmas (Billig, 1989, 2012; van Dijk, 1987, 1992; Wetherell, 2012; Wetherell and Potter, 1992; Condor, 2000; Tileagă, 2005: 604; and for studies in Greece in particular see Figgou and Condor; 2006a, 2006b; Bozatzis, 2009; Kadianaki, 2010 for immigrant identity dialogues and strategies of resistance in Greece).

Although our main focus was analytic, another contribution attempted by this article was a theoretical and methodological merging between DP and argumentation studies. One example of this concerns equipping argumentation studies with a view to the context of argumentative discussions: the integration allowed approaching our specific argumentative exchanges from a perspective which pays attention to the development of contextually and socially shared themes, to speakers' identities and to the affordances made for others, helping to tackle themes such as security and identity - as topic - in conjunction with local identity management. The analysis was, therefore, conducted from the vantage point of attending to the social and political significance of holding strong views and of denial strategies, thus, with paying attention not only to 'members' methods and accountability' but also to the 'collective and social patterning of background normative conceptions, their forms of articulation and the social and psychological consequences' (Wetherell, 1998: 405). For DP, taking into account the perspective of argumentation studies meant considering rhetorical and discursive strategies in the context of an argumentative discussion between a protagonist and an antagonist who manoeuver strategically to defend their standpoints. The combination of these approaches allowed a fine-grained analysis of parental positioning and topicalization as a form of denial of racism in terms of micro-analytic techniques as well: for example, referring to argument schemes in accordance with argumentation studies allowed associating the level of discursive strategies to a more abstract level as regards the bases on which strong views are supported and/or criticized.

\section{References}

Antaki C, Condor D and Levine M (1996) Social identities in talk: Speaker's own orientations. British Journal of Social Psychology 35: 473-492.

Billig M (1985) Prejudice, categorization and particularization: From a perceptual to a rhetorical approach. European Journal of Social Psychology (EJSP), 15, pp. 79-103.

Billig M (1987) Arguing and Thinking. A rhetorical approach to social psychology. Cambridge: CUP.

Billig M (1989) The argumentative nature of holding strong views: A case study. EJSP 19: 203-223.

Billig M (1991) Ideology and Opinions. Studies in Rhetorical Psychology. London: SAGE. 
Billig M 1996 (2 $2^{\text {nd }}$ edition). Arguing and thinking: A rhetorical approach to social psychology. Cambridge: CUP.

Billig M (2001) Discursive, Rhetorical and Ideological Messages. In: Wetherell M, et al (eds) Discourse Theory and Practice: A Reader. London: SAGE, pp. 211-221.

Billig M (2012) The notion of 'prejudice': some rhetorical and ideological aspects. In: Dixon J and Levive M (eds) Beyond Prejudice: Extending the Social Psychology of Conflict, Inequality and Social Change. Cambridge: CUP, pp. 139-157.

Billig M, Condor S, Edwards D, Gane M, Middleton D and Radley A (1988) Ideological Dilemmas: a social psychology of everyday thinking. London: SAGE.

Bozatzis N (2009) Occidentalism and accountability: constructing culture and cultural difference in majority Greek talk about the minority in Western Thrace. Discourse \& Society (D\&S) 20(4): 431-453.

Caffi C (2007) Mitigation. Amsterdam (etc.): Elsevier.

Clauss P (2007) Prolepsis: Dealing with multiple viewpoints in argument. In: Hansen HV et al (eds) Dissensus and the Search for Common Ground (CD-ROM). Windsor ON: OSSA, pp. 1-17.

Coleman D and Salt J (1992) The British population: Patterns, trends and processes. Oxford: OUP.

Condor S (2000) Pride and Prejudice: identity management in English people's talk about 'this country'. $D \& S$ 11(2): 175-205.

Edwards D (2000) Extreme Case Formulations: Softeners, Investment, and Doing Nonliteral. Research on Language and Social Interaction 33(4): 347-373.

Edwards D (2005) Discursive psychology. In: Fitch KL and Sanders RE (eds) Handbook of Language and social interaction. Mahwah, NJ: Erlbaum, pp. 257-273.

Edwards D and Potter J (1992) Discursive Psychology. London: SAGE.

Figgou L and Condor S (2006a) Irrational categorisation, natural intolerance and reasonable discrimination: Lay representations of prejudice and racism. British Journal of Social Psychology Vol. 45 (2): 219-43.

Figgou L and Condor S (2006b) Categorising Category Labels in Interview Accounts about the 'Muslim Minority' in Greece. Journal of Ethnic and Migration Studies Vol. 33 (3): 439-459.

Figgou L, Sapountzis A, Bozatzis N, Gardikiotis N and Pantazis P (2011) Constructing the Stereotype of Immigrants' Criminality: Accounts of Fear and Risk in Talk about Immigration to Greece. Journal of Community \& Applied Social Psychology. 21: 164177.

Gaertner SL and Dovidio JF (2005) Understanding and addressing contemporary racism: From aversive racism to the Common Ingroup Identity Model. Journal of Social issues 61(3): 615-639. 
Garssen B (2001) Argument schemes. In: van Eeemeren FH (ed) Crucial concepts in argumentation theory. Amsterdam: Sic-Sat, pp. 81-99.

Goffman E (1967) On face-work: an analysis of ritual elements in social interaction. In: Goffman E (ed) Interaction Ritual: Essays on Face-to-Face Behaviour. NY: Pantheon Books, pp. 5-45

Goffman E (1981) Forms of Talk. Pennsylvania: University of Pennsylvania Press.

Greco Morasso S (Forthcoming) Multivoiced decisions. A study of migrants' inner dialogue and its connection to social argumentation. Pragmatics \& Cognition.

Hamilton DL and Gifford RK (1976) Illusory correlation in interpersonal perception: A cognitive basis of stereotypic judgments. Journal of Experimental Social Psychology 12: $392-407$

Hewitt JP and Stokes R (1975) Disclaimers. American Sociological Review 40(1): 1-11.

Ihnen C and Richardson JE (2011) On combining Pragma-Dialectics with Critical Discourse Analysis. In: Feteris E et al (eds) Keeping in touch with Pragma-Dialectics. Amsterdam: Benjamins, pp. 231-243.

Jefferson G (1990) List contraction as a task and resource. In: Psathas G (ed) Interaction Competence. Washington, DC: University Press of America, pp. 63-92.

Leff M (1999) Rhetorical Prolepsis and the Dialectical Tier of Argumentation. In: van Eemeren FH et al (eds) Proceedings of the Fourth International ISSA Conference . Amsterdam: SIC-SAT, pp. 510-513.

Leff M and Goodwin J (2000) Dialogic figures and dialectical argument in Lincoln's rhetoric. Rhetoric \& Public Affairs 3(1): 59-69.

Lock A and Strong T (2010) Social Constructionism. Cambridge: CUP.

Maroukis Th (2012) The number of irregular immigrants in Greece at the end of 2010 and 2011. ELIAMEP Briefing Notes.

NSSG (National Statistical Service of Greece) Statistical Yearbook 2001. Athens: NSSG.

Parker I (1989) Discourse and Power. In: Shotter J and Gergen KJ (eds) Texts of Identity. London: SAGE, pp. 56-69

Plantin C (2002) Argumentation studies and discourse analysis: The French situation and global perspectives. Discourse Studies 4(3): 343-368.

Pomerantz A (1986) Extreme Case Formulations: A way of legitimizing claims. Human Studies 9: 219-229.

Potter J (1996) Representing Reality: discourse, rhetoric and social construction. London: SAGE.

Potter J (2012) Discourse analysis and discursive psychology. In: Cooper H (ed) APA handbook of research methods in psychology (Vol. 2).. Washington: American Psychological Association Press, pp. 111-130. 
Potter J and Wetherell M (1987) Discourse and Social Psychology: Beyond Attitudes and behaviour. London: SAGE.

Rigotti E (2005) Towards a typology of manipulative processes. In: de Saussure L and Schulz $\mathrm{P}$ (eds) New perspectives on manipulative and ideological discourse in pragmatics and discourse analysis. Amsterdam: Benjamins, pp. 257-274.

Rigotti E and Greco S (2005) Introducing argumentation. www.argumentum.ch [January $2^{\text {nd }}$, 2013].

Rigotti E and Greco Morasso S (2009) Argumentation as object of interest and as social and cultural resource. In: Muller Mirza N and Perret-Clermont A-N (eds) Argumentation and education. NY: Springer, pp. 9-66.

Rigotti E and Greco Morasso S (2010) Comparing the Argumentum Model of Topics to other contemporary approaches to argument schemes: the procedural and material components. Argumentation 24(4): 489-512.

Schneider S (2010) Mitigation. In: Locher MA and Graham SL (eds) Interpersonal pragmatics. Berlin/NY: De Gruyter pp. 253-269.

Snoeck Henkemans AF (2007) Commentary on Patrick Clauss: Prolepsis: Dealing with multiple viewpoints in Argument. In: Hansen HV et al (eds) Dissensus and the Search for Common Ground (CD-ROM). Windsor, ON: OSSA, pp. 1-4.

Tileagă C (2005) Accounting for extreme prejudice and legitimating blame in talk about the Romanies. $D \& S$ 16(5): 603-624.

Van Dijk TA (1987) Communicating racism: Ethnic prejudice in thought and talk. London: SAGE.

Van Dijk TA (1992) Discourse and the denial of racism. D\&S 3: 87-118.

Van Dijk TA (1995) Ideological Discourse Analysis. Interdisciplinary approaches to Discourse Analysis 4: 135-161.

Van Dijk TA (2012) Discourse and Knowledge. In: Gee, JP and Handford M (Eds.), Handbook of Discourse Analysis. London: Routledge, pp. 587-603.

Van Eemeren FH and Grootendorst R (1987) Fallacies in pragma-dialectical perspective. Argumentation 1(3): 283-301.

Van Eemeren FH and Grootendorst R (2004) A systematic theory of argumentation: The pragma-dialectical account. Cambridge: CUP.

Van Eemeren FH and Houtlosser P (2002) Strategic Manoeuvring: Maintaining a Delicate Balance. In: van Eemeren FH and Houtlosser P (eds) Dialectic and rhetoric: The warp and woof of argumentation analysis. Dordrecht: Kluwer, pp. 131-159.

Van Eemeren FH and Houtlosser P (2009) Seizing the occasion: Parameters for analysing ways of strategic manoeuvring. In: van Eemeren FH and Garssen B (eds) Pondering on Problems of Argumentation. NY: Springer, pp. 3-14. 
Van Eemeren FH (2010) Strategic Manoeuvring in Argumentative Discourse. Amsterdam: Benjamins.

Vertovec S (2007) Super-diversity and its implications. Ethnic and Racial Studies 30(6): 1024-1054.

Wetherell M (2012) The prejudice problematic. In: Dixon J and Levive M (eds) Beyond Prejudice: Extending the Social Psychology of Conflict, Inequality and Social Change. Cambridge: CUP, pp. 158-178.

Wetherell M (1998) Positioning and interpretative repertoires: Conversation analysis and post-structuralism in dialogue. $D \& S$ 9: 387-412.

Wetherell M and Potter J (1992) Mapping the Language of Racism: Discourse and the Legitimation of Exploitation. NY: Columbia University Press.

Wimmer A and Schiller NG (2002) Methodological nationalism and beyond: nation-state building, migration and the social sciences. Global Networks 2(4): 302-334.

Xenitidou M (2007) Talking about Greekness and migration in Central Northern Greece: The construction of multiple categories of Greeks as the 'ultimate contract' for migration? $3 \mathrm{rd}$ LSE PhD Symposium on Contemporary Greece. London, 14-15 June.

Xenitidou M (2010) National Identity and Otherness: Greek Speakers' Talk about Migration. Saarbrücken, Germany: LAP.

Xenitidou M and Kokkali I (submitted) Identity Construction and Negotiation in the context of Migration: Comparing Greek and Albanian Lay Discourses in Greece. IMR.

Zittoun, T (2009) Dynamics of life-course transitions: A methodological reflection. In: Valsiner J et al (eds) Dynamic process methodology in the social and developmental sciences. NY: Springer, pp. 405-430.

\footnotetext{
Notes

${ }^{\mathrm{i}}$ For DP these goals do not pre-exist as such but are guided by the normativities of argumentative discourse: reasonableness and truth claims.

ii This approach has been developed by a research group at the Università della Svizzera Italiana, Institute of Argumentation, Linguistics and Semiotics (Rigotti and Greco Morasso, 2009).

iii Other definitions conflate with our take on these phenomena, e.g. slightly different definitions of bushes and shields in have been proposed in linguistic pragmatics (Schneider, 2010); in sociological studies, hedging has been treated as a type of disclaimer in signalling minimal commitment to what is being said and uncertainty about how it will be received (Hewitt and Stokes, 1975).

iv At the time of the first study, the percentage contribution of immigrants to the indigenous (adjusted) population was estimated at $10.3 \%$ (NSSG, 2001). At the time of writing this article (2012-3), estimates are that the immigrant population approximates $839,136,8.5 \%$ of the total population of Greece (Maroukis, 2012).

v In Northern Greece in particular, immigrants come from the neighbouring country of Albania (Maroukis, 2012).

${ }^{\mathrm{vi}}$ Funded by the Swiss National Science Foundation (PBTIP1-133595, 2010- 2012)

vii In the extracts with participants in London, numeration of lines is relative to the selected excerpt of the interview only.

viii Thessaloniki and the old centre where Vera lives had a strong Jewish element but also features 'invisible' prayer houses from the Ottoman Empire. Albanians, the main immigrant population in Northern Greece, were invariably Muslim, at least upon arrival to Greece.

ix In this case, 'little ones' does not represent a bush because it is not part of a mitigation strategy.
} 